\title{
The Issues Affecting Mental Health Nursing in Uganda
}

\author{
Jan Bailey \\ University of Chester, United Kingdom \\ *Corresponding author: Jan Bailey, University of Chester, UK; Tel: 42073224 40; E-mail: j.bailey@chester.ac.uk
}

Received Date: April 16, 2014, Accepted Date: September 23, 2014, Published Date: September 30, 2014

Copyright: @ 2014, Jan Bailey. This is an open-access article distributed under the terms of the Creative Commons Attribution License, which permits unrestricted use, distribution, and reproduction in any medium, provided the original author and source are credited.

\begin{abstract}
Estimates are that up to $35 \%$ of the Ugandan populations have a mental health condition; however access to psychiatric care, particularly for people living in rural areas, is poor. Additionally, cultural and lay beliefs and stigma affect both the individual with mental illness and healthcare professionals. The Ugandan government has recognized the need to modernize legislation and develop policies designed to provide modern psychiatric services to the whole population. Strategies include, passing new legislation, integrating services into primary care, including psychiatric illness in nurse education. Nevertheless, evidence suggests that this rhetoric is not being fully enacted. This paper reviews the issues affecting the development and delivery of improved mental health services, with a particular focus on psychiatric nursing. Actions that have already successfully addressed issues with psychiatric services in Uganda are highlighted and conclusions drawn regarding the development of future services.
\end{abstract}

\section{Introduction}

In 2011 the World Health Organization reported that mental illness accounted for $13 \%$ of the global disease burden and that resources to address this are inadequate, especially in lower income countries [1]. This report also highlights global inequality and that people living in low income countries are less likely to have access to out-patient services, be consulted about mental health care or to be covered by mental health legislation than people living in high income countries [1]. Uganda is a land locked country in east Africa 241,038 square kilometers in size and in 2011 its fast growing population stood at 33 million [2]. In 2012 an estimated 7.5 million Ugandans lived in poverty with $94.4 \%$ of these living in rural areas making Uganda one of the world's poorest countries [3]. Estimates of the rates of mental illness in Uganda vary, although the Ugandan Government Health Sector Strategic Plan iii (HSSPiii) states that mental illness accounts for $13 \%$ of all health conditions in the country while another report suggests that $35 \%(9,574,915)$ of the Ugandan population are living with a mental health condition $[4,5]$.

The antecedents to mental illness in east Africa include the HIV/ AIDS pandemic, conflict, natural disasters and poverty with evidence of a correlation between poverty and mental ill health [5-7]. Furthermore, evidence suggests that up to $50 \%$ of people affected by conflict develop post-traumatic stress disorder (PTSD) [8]. Uganda has experienced years of conflict, including over 25 years opposition to the government by the Lord's Resistance Army, which is notorious for attacking civilians, as well as abducting children; forcing girls into sexual slavery and boys to fight as soldiers [9]. Uganda is also home to thousands of refugees from neighboring countries, for example over 66,000 people displaced from the Democratic Republic of Congo [10]. It is possible to postulate therefore that conflict has contributed to the prevalence of mental illness in Uganda. Indeed, as well as PTSD, depression, anxiety, and substance misuse are also commonly triggered by conflict and high rates of these conditions are found among people living in Northern Uganda [11].

While there is clear evidence of the need for psychiatric services and the Ugandan government recognizes this, research suggests that the available resources do not have the capacity to address the population's needs, resulting in limited access to mental health services [12]. A review of Uganda's public mental health care provision, undertaken using the WHO-AIMS tool, found that only $1 \%$ of government healthcare spend was directed to primary care psychiatric services [12]. A study focusing on all mental health services in Uganda found that $\$ 16,705,614$ of the $\$ 252,673,400$ total health budget, equating to $\$ 0.56$ per capita, was ring fenced for all mental health services. Of this amount, $\$ 14,160,000(85 \%)$ was directed to the only national psychiatric hospital in the country-Butabika hospital [13]. As a consequence of being the only specialist psychiatric hospital, at times Butabika can have 1200 patients with over half having acute mental illness [14]. Other psychiatric services in the country include 27 community-based psychiatric in-patient units equating to 1.4 beds per 100,000 of the population. However, these units are part of general hospitals with no specialist community psychiatric hospitals in the country [1]. Additionally, the majority of services (62\%) are situated in urban areas, thus people living in rural areas have to travel long distances to access treatment [15].

There is also a lack of other relevant services with outpatient services being under-resourced and no provision for specialized services for children or adolescents $[15,16]$. Although, the Butabika East London Link has recently opened the first children's psychiatric ward in the country [17]. Given the high number of displaced people in Uganda and that evidence suggests that over $60 \%$ of displaced children under the age of five have witnessed or experienced violence, this is a crucial issue [18]. The provision of psychiatric care for older people is also problematic; with research showing that only $6 \%$ of older in-patients in general wards had a diagnosis of mental illness but, when measured, their actual morbidity was $48 \%$ [19]. Additionally there is very little community support and rehabilitation available [15], even though research demonstrates the success of outreach services [15]. Neither is there a clear mechanism for referring people from tertiary/secondary care back to primary care [1]. 
Page 2 of 5

\section{Government Strategy}

The HSSPiii acknowledges that there are serious issues regarding the provision of psychiatric care, recognizing that the existing services are hindered by a number of factors including, a lack of staff and other resources, as well as problems with mental health legislation, and negative attitudes towards psychiatric services from some people working in healthcare [4]. Increased access to and improved mental health services is recognized as a priority, placing a focus on modernizing legislation, developing a cohesive mental health policy, raising awareness of mental illness, training health professionals - in clinical skills and attitudes towards mental health - and promoting patients' rights. Evidence suggests that mental health services delivered in the local community result in better outcomes [20]. The Ugandan government's targets for prevention and treatment of mental illness include, providing mental healthcare at all Regional Referral Hospitals, increasing access to mental health units by $50 \%$, and integrating mental health care into primary care [4]. Indeed, the Ugandan government policy of decentralizing mental healthcare and modernizing services has been in place since 1996 and mental health care is included in the country's minimal healthcare package [8].

Nevertheless, a review of compliance with the WHO (2001) recommendations found that there remain serious issues regarding integrating mental health care into primary care [21]. These issues included a failure to implement policy, a lack of appropriate medication, lack of trained staff, as well as continuing negative attitudes towards mental health and working with people with mental health conditions. Consequently, although services are being decentralized, people with mental health conditions are often treated as general patients and still do not have access to the specialized services they need.

\section{Specific Issues Influencing Service Delivery}

\section{Nurse education}

Research into the barriers to up scaling psychiatric services in low and middle income countries highlights that a lack of trained staff and a resistance to decentralisation of mental health services are key issues [22]. Research suggests that Uganda has a serious lack of trained psychiatric staff; in 2010 there were only 0.78 trained psychiatric nurses per 100,000 of the population with the majority working at Butabika hospital and one district had only one trained psychiatric nurse [12,23]. Even with the high percentage of the country's psychiatric nurses working at Butabika, that hospital still has staff shortages with only 180 psychiatric nurses against a required cadre of 260 [24].

Psychiatric nurse education is also problematic with only one specialized course in the whole country which is based at Butabika hospital. One recommendation is that that mental health training for general nurses should be increased [25]. Indeed Ugandan general nurse education aims to produce multi-skilled professionals with psychiatry being an integral part of the curriculum [26]. Evidence shows that psychiatric nursing is part of the nursing and medical curricula at Makerere University and the researchers postulate that this is adequate to meet government aspirations [27]. However, research found that only $3 \%$ of general nurse training in Uganda covers mental health and that, in reality, few nurses have any training in psychiatric nursing [12]. Furthermore, of those nurses who have had such training, few see their role as being other than identification of mental health conditions and referral to other services [12]. The attitudes of staff and managers towards mental illness are recognized as a key challenge to the delivery of quality psychiatric care and the emphasis on ethics and awareness of patients' human rights in the nursing curricula needs strengthening [28,27].

Access to continuing professional development and higher level training for qualified nurses can also be problematic. Nurses' managers have control over training and evidence shows that, although staff have the desire to deliver quality care, they have to deal with social relationships and negotiate with managers who control both their access to training and their salary [29]. This also influences in staff motivation and their delivery of equitable and quality care to their patients. Furthermore, staff shortages also contribute to healthcare professionals being refused time to attend training and development opportunities [26].

However, the picture is not entirely bleak with excellent initiatives underway that have resulted in improved staff training and development. The Butabika East London Link initiative is a multidisciplinary, long term, project designed to improve mental health in Uganda [17]. One of the major aspects of this initiative is improved staff training, particularly for Psychiatric Clinical Officers and a focus on aggression management, which has seen both a reduction in violence within mental health units and changes in staff attitudes. This successful on-going initiative involves a range of actions including staff visits to the UK, the delivery of staff training and user involvement [17].

\section{Other health and social care professionals}

There is evidence that, in addition to a lack of qualified psychiatric nurses, there is a need for other professionals working in Ugandan health provision to be trained in mental health care and rehabilitation. Indeed, it may be suggested that the role other professionals have in mental health care has been somewhat neglected, for example a 2006 review of Ugandan mental health policy found no mention of allied professionals such as social workers [12]. Indeed, research shows that there are very low numbers of psychologists, social workers and occupational therapists working in mental health care with only 0.01 from each profession per 100,000 of the population [12,25]. Furthermore, only at Butabika hospitals are there healthcare professionals, other than doctors or nurses, working in psychiatric services [2].

This paucity of specialist staff has implications for individuals with mental illness and for health professionals themselves. The benefit of multi-disciplinary teams is that they can provide holistic care, promoting the recovery of individuals and in doing so also enhance the skills and experience of the team members. Moreover, appropriately trained social workers can support people in the community; perhaps even preventing hospital admission, as well as helping them reintegrate into society at hospital discharge. While the lack of allied health professionals may reduce the effectiveness of treatment it also has a concomitant impact on nurses. Inability to refer to other services may increase their workload and the scope of issues nurses are expected to address, creating additional pressure on an already stretched workforce.

\section{Recruitment and retention of nurses}

In common with the training of other healthcare professionals in Uganda, psychiatric nurses participate in community based education, 
Page 3 of 5

which provides opportunities to develop and strengthen their practice skills $[27,30]$. To prepare nurses to work outside urban areas it has been recommended that some schools of nursing should be sited in rural areas and placements in rural areas are increased [26]. This is consistent with the aim of decentralizing health service delivery. It must be considered however that decentralization of services is not straightforward; there is evidence that some healthcare professionals do not want to work in rural areas, which impacts on recruitment and retention of staff $[26,31,32]$. Antecedents to this reluctance to work in rural areas include a lack of progression opportunities, a lack of structural resources and little access to psychotropic drugs [26]. Additionally, $81 \%$ of student nurses asked said that they did not feel that it was safe to work in rural areas [3]. However, research suggests that nurses form attachments to areas where they do their training, thus an increase in community based training could improve recruitment to rural areas [27].

The lack of resources, including the most basic, such as clean water and electricity as well as the appropriate drugs, impacts on the ability of staff to deliver the quality of care they aspire to and reduces morale and job satisfaction $[26,33]$. Furthermore, there is evidence that nurses are often scapegoated by the media, politicians and service users for the lack of resources, being accused of stealing drugs and patient neglect [26]. Consequently, relationships between nurses and the community may be poor with $20 \%$ of nurses reporting being verbally abused and/or physically assaulted by patients and/or their families [26]. Furthermore 25\% report that they had been abused by their manager [29]. Social and power relationships have also emerged as an important influence on the ability to deliver quality compassionate care, thus empowering staff and addressing dysfunctional relationships are crucial in motivation and the successful decentralization of services [29].Unsurprisingly, job satisfaction among Ugandan healthcare professional is low with as many as $70 \%$ stating that they are likely to migrate outside of Uganda to work $[29,31]$. The much higher salaries available in other countries such as the USA and UK were identified as primary drivers in this [31]. Being respected, having access further training and career advancement also influence migration patterns [26].

\section{Cultural Issues}

\section{The stigma of mental illness}

The 2001 report 'Mental Health: New understanding, New Hope' recognized that mental illness is widely stigmatized and this influences how it is addressed and whether people will actually access services [34]. Indeed, the stigma of mental illness may be 'more destructive and disabling than the illness itself. People with mental illness living in Uganda remain stigmatized and experience widespread discrimination, exploitation and exclusion including, social exclusion, being isolated by family and friends, being refused financial services, and being denied employment $[7,16,35]$. Furthermore, the current mental health act which dates from 1964 has been described as being "outdated and offensive'.

Research highlights that the main purpose of this act is to facilitate compulsory detention of the mentally ill and its wording results in the acceptance of their maltreatment both in hospital and the community [15]1. The Ugandan government recognizes that existing mental health law is outdated and that there is a need to tackle stigma; addressing this in its revised mental health policy [36]. Nonetheless, at the time of writing, the mental health act of 1964 remains in force.
Additionally, it is concerning that an evaluation of the development of Ugandan mental health policy reported that some stakeholders, both lay people and professionals, held a negative concept of mental illness and proposed interventions, and that some treatment contravened human rights legislation [37]. Indeed previous research identified that some people in power, including politicians, stigmatized mental illness and also did not understand how to tackle stigma [28]. There is also evidence that non-clinical staff in Ugandan hospitals may stigmatize mental illness; hospital administrators were found to be resistant to buying psychotropic drugs and were dismissive of patients who had mental illness [28]. Furthermore, medical staff working with patients with mental illness did not view this as their main role, with the researchers postulating that this reflects a widespread stigmatization of mental illness [23]. Evidence also suggests that healthcare professionals give mental illness a lower priority than other illness. [7]. Additionally, an analysis of the decentralization of psychiatric services highlights: (the) stigma associated with mental illness, which appears to still be pervasive amongst general health care workers'.

Research with service users' highlights that they are aware of the negative attitudes of some healthcare workers; they reported feeling that psychiatric staff stigmatized and stereotyped people with mental illness [31]. However, there is also evidence of people working in healthcare being sympathetic toward people with mental illness. Additionally, the stigma attached to mental illness is not restricted to individuals living with it; evidence suggests that psychiatry is stigmatized by other healthcare professionals, and that psychiatric services per se are stigmatized [29,31].

Addressing the stigmatization of mental illness in Uganda has been recognized as a priority by the government and health professionals, and work in this area is underway. For example, staff involved in the Butabika East London Link is working with traditional healers to address the stigma of epilepsy and with staff to address their attitudes towards psychiatric patients. A key aspect of this work is the Heart sounds project which gives services users a voice and offers support from peers in the UK. The project also provides an internet café and support in Kampala [40]. Rural outreach services also recognize the necessity to involve traditional healers and local people, as well as health professionals. While this last project did not set out to specifically tackle stigma, it included raising the awareness of mental illness in schools and the community with the researchers reporting a subsequent reduction in the stigmatization of mental illness.

\section{Lay perceptions of mental health and its treatment}

Culture influences the understanding and treatment of mental illness in Uganda [41]. It is common for lay people in Uganda to attribute a supernatural antecedent to mental illness; these supernatural causes include witchcraft, spirit possession, failure to observe cultural traditions, and poor relationships with the dead [5,31,41-43]. Some also hold the belief that mental illness is contagious. Evidence shows that these beliefs influence people's reaction to mental illness and how they seek to address it; many use traditional healers or seek help from their church before accessing mainstream medical services $[38,41]$.

However, there is evidence that for some conditions termed 'Kizungu madness', traditional healers assigned antecedents such as HIV/AIDS, malaria, inheritance and substance abuse; in these instances they referred the individual to mainstream services $[41,43]$. As faith in traditional healers is common in Uganda, the establishment 
Page 4 of 5

of mutual respect between traditional healers and the mainstream services can be an important factor in the success of outreach projects [7]. The establishment of such relationships in that project resulted in traditional healers referring people to mainstream services, while healthcare professionals did not attempt to deter people from traditional healers. Consequently, the project workers saw increased motivation to seek help for mental health issues.

\section{Conclusion}

There is strong evidence that there remains an on-going need for modern, accessible psychiatric services in Uganda, especially in rural areas where people still have to travel long distances to access help. It is positive that the Ugandan government recognizes the need to develop additional and more effective psychiatric services and has included this in the HSSPiii, setting targets to improve services and integrate them into primary care. Nonetheless, although some action has been taken there is also evidence that the rhetoric is not being fully enacted and access to psychiatric services remains restricted with still only one specialist hospital and one specialized school of nursing in the country. This could be addressed by siting training in rural areas and by improving mental health training for general nurses [25-27,44].

Furthermore, research shows that mental illness remains widely stigmatized by lay people and those in power, as well as by some healthcare professionals; this both deters people from seeking help and from receiving the appropriate care and treatment when they do. There is evidence that it is difficult to recruit people into psychiatric services; the stigma associated with mental illness and the fact that this is extended to include psychiatric services may be one explanation for this. However, it is important to recognize that there is a crisis in recruitment and retention of nurses per se in Uganda and this must be understood and addressed before the quality and provision of services can be improved. Nonetheless, it is clear that tackling stigma is a key issue that should be considered when developing and implementing a strategy to improve psychiatric services in Uganda.

Although achieving the aim of modern accessible psychiatric services for the whole of Uganda is a long term goal, there is already work underway that has begun to tackle key issues and such work provides an evidence base for the best way forward. Recognizing the importance of culture is a vital factor in addressing how mental illness is perceived and addressed; evidence demonstrates that a collaborative approach between mainstream services and traditional healers may be beneficial [41]. Indeed, the effectiveness of staff training, user involvement and a collaborative approach between the community, health professionals and traditional healers has been demonstrated $[7,17]$. It can be proposed, therefore, that implementing such initiatives, especially in rural areas, may well be the most practical route to improving psychiatric services in Uganda.

\section{References}

1. World Health Organization (2011) Mental Health Atlas.

2. Ndyanabangi S, Funk M, Ssebunnya J, Drew N, Dhillon S, et al. (2012) WHO Profile on mental health in development (WHO proMIND). Republic of Uganda, World Health Organization Geneva.

3. The State of Uganda (2012) Population Report.

4. Government of Uganda, Ministry of Health (2010) Health Sector Strategic Plan (iii), 2010/11-2014/15.
5. Chronic Poverty Research Centre (2007) Mental Illness and Exclusion: Putting Mental Health on the Development Agenda in Uganda. Policy briefs no $2 / 2007$.

6. Njenga F (2002) Focus on psychiatry in East Africa. British Journal of Psychiatry 18: 354-359.

7. Byaruhanga E, Cantor-Graae E, Maling S, Kabakyenga J (2008) Pioneering work in mental health outreaches in rural, south western Uganda. Intervention 6: 117-131.

8. World Health Organization (2001) Mental Health: New Understanding, New Hope.

9. United Nations (2013) Security Council urges regional cooperation to tackle Lord's Resistance Army threat.

10. Relief web (2013).

11. Baingana F, Mangen PO (2011) Scaling up of mental health and trauma support among war affected communities in northern Uganda: lessons learned. Intervention 9: 291-303.

12. Kigozi F, Ssebunnya J, Kizza D, Cooper S, Ndyanabangi S, MHaPP (2011) An overview of Uganda's mental health care system: results from an assessment using the world health organization's assessment instrument for mental health systems (WHOAIMS). International Journal of Mental Health Systems 4: 1.

13. Raja S, Wood SK, de Menil V, Mannarath SC (2010) Mapping mental health finances in Ghana,Uganda, Sri Lanka, India and Lao PDR International Journal of Mental Health Systems 4: 11.

14. Tropical Health and Education Trust (2013) Improvising Mental Health in Uganda.

15. Cooper S, Ssebunnya J, Kigozi F, Lund C, Flisher A (2010) The Mhapp Research Programme Consortium (MHaPP): Viewing Uganda's mental health system through a human rights lens. International Review of Psychiatry. 22: 578-588.

16. Kleintjes S, Lund C, Flisher AJ (2010) MHaPP Research Programme Consortiu: A situational analysis of child and adolescent mental health services in Ghana, Uganda, South Africa and Zambia. African Journal of Psychiatry 13: 132-139.

17. Butabika East London Link (2013).

18. McCabe S (2005) Uniting the Family of Psychiatric Nurses: Commonalities and Divergences in the Nursing Lives We Lead. Perspectives in Psychiatric Care 4: 35-41.

19. Nakasujja N, Musisi S, Walugembe J, Wallace D (2007) Psychiatric disorders among the elderly on non-psychiatric wards in an African setting. International Psychogeriatrics19: 691-704.

20. Wiley-Exley E (2007) Evaluations of community mental health care in low- and middle-income countries: A 10-year review of the literature. Social Science and Medicine 64: 1231-1241.

21. Bhana A, Petersen I, Baillie KL, Flisher AJ (2010) The MHAPP Research Programme Consortium Implementing the World Health Report 2001 recommendations for integrating mental health into primary health care: A situation analysis of three African countries: Ghana, South Africa and Uganda International Review of Psychiatry 22: 599-610.

22. Saraceno B, van Ommeren M, Batniji R, Cohen A, Gureje O, et al. (2007) Barriers to improvement of mental health services in low-income and middle-income countries. The Lancet 370: 1164-74.

23. Ssebunnya J, Kigozi F, Kizza D, Ndyanabangi S (2010) MHaPP Research Programme Consortium: Integration of Mental Health into Primary Health Care in a rural district in Uganda. African Journal of Psychiatry 13: $128-131$

24. New Vision (2013).

25. World Health Organization and Ministry of Health Uganda (2006) WHO-AIMS Report on Mental Health System in Uganda.

26. Voluntary Service Overseas (2012) Our Side of the Story: The lived experience and opinions of Ugandan health workers. ISBN: 978: 1903697-337.

27. Kiguli S, Baingana R, Paina L, Mafigiri D, Groves S, et al. G (2011) Situational analysis of teaching and learning of medicine and nursing 
students at Makerere University College of Health Sciences. BMC International Health and Human Rights 11: S3.

28. Ssebunnya J, Kigozi F, Lund C, Kizza D, Okello E (2009) Stakeholder perceptions of mental health stigma and poverty in Uganda BMC International Health and Human Rights 9:5.

29. Chandler CIR, Kizito J, Taaka L, Nabirye C (2013) Aspirations for quality health care in Uganda: How do we get there? Human Resources for Health 11: 11-12.

30. Kaye D, Mwanika A, Burnham G, Chang LW, Mbalinda SN, et al. (2011) BMC International Health and Human Rights 11.

31. Nguyen L, Ropers S, Nderitu E, Zuyderduin A, Luboga S et al. (2008) Intent to migrate among nursing students in Uganda: Measures of the brain drain in the next generation of health professionals. Human Resources for Health 6: 1478-4491-6-5.

32. Hagopian A, Zuyderduin A, Kyobutungi N and Yumkella F (2009) Job Satisfaction and Morale in the Ugandan Health Workforce. Health Affairs 28: 863-87.

33. Fournier B, Kipp W, Mill J, Walusimbi M (2007) Nursing Care of AIDS Patients in Uganda. Journal of Transcultural Nursing 18: 257-284.

34. Nsereko JR, Kizza D , Kigozi F, a Ssebunnya J, Ndyanabangi S, et al. (2011) MHaPP Research Programme Consortium .Stakeholder's perceptions of help seeking behaviour among people with mental health problems in Uganda. International Journal of Mental Health Systems 5: 5.

35. Okello ES (2006) Cultural explanatory models of depression in Uganda. Karolinska University Press ISBN 9: 7140-823-1.
36. Omar MA, Green AT, Bird PK, Mirzoev T, Flisher AJ, et al. (2010) Mental health policy process: a comparative study of Ghana, South Africa, Uganda and Zambia International Journal of Mental Health Systems 4: 24.

37. Ssebunnya J, Kigozi F, Ndyanabangi S (2012) Developing a National Mental Health Policy: A Case Study from Uganda. PLoS Medicine 9: 10.

38. Petersen I, Bhana A, Campbell-Hall V, Mjadu S, Lund C, et al. (2009) the Mental Health and Poverty Research Programme Consortium. Planning for district mental health services in South Africa: a situational analysis of a rural district site. Health Policy and Planning 24: 140-150.

39. Oguva EBL, Buga J, Odoke H, Boardman J (2002) Promoting psychiatry in the medical school. The case of Uganda. Psychiatric Bulletin 26: 194-195.

40. Heartsounds (2013).

41. Teuton J, Bentall R, Dowrick C (2007) Conceptualizing Psychosis in Uganda: The Perspective of Indigenous and Religious Healers. Transcultural Psychiatry 44: 79 -114.

42. Ovuga E, Boardman J, Olika EGAO (1999) Traditional healers and mental illness in Uganda. Psychiatric Bulletin 23: 276-279.

43. Abbo C, Okello E, Ekblad S, Waako P, Musisi S (2008) Lay concepts of psychosis in Busoga,

44. Eastern Uganda: A pilot study. World Cultural Psychiatry Research Review 3: 132-145.

45. Kigozi F, Ssebunnya J, Kizza D, Ndyanabangi S, Green A, et al. (2008) A situational analysis of the Mental health Systems: a phase 1 country report. 